\title{
Comparison of optimization techniques for MRR and surface roughness in wire EDM process for gear cutting
}

\author{
K.D. Mohapatra ${ }^{a^{*}}$, M.P. Satpathy ${ }^{a}$ and S.K. Sahoo ${ }^{a}$
}

${ }^{a}$ Department of Mechanical Engineering, National Institute of Technology, Rourkela, India

\begin{tabular}{|c|c|}
\hline CHRONI CLE & ABSTRACT \\
\hline $\begin{array}{l}\text { Article history: } \\
\text { Received February } 42016 \\
\text { Received in Revised Format } \\
\text { August } 162016 \\
\text { Accepted September } 82016 \\
\text { Available online } \\
\text { September } 82016 \\
\text { Keywords: } \\
\text { Dedendum } \\
\text { Desirability } \\
\text { Gear } \\
\text { Surface roughness } \\
\text { Taguchi orthogonal design } \\
\text { Wire tension }\end{array}$ & $\begin{array}{l}\text { The objective of the present work is to use a suitable method that can optimize the process } \\
\text { parameters like pulse on time (TON), pulse off time (TOFF), wire feed rate (WF), wire tension } \\
\text { (WT) and servo voltage (SV) to attain the maximum value of MRR and minimum value of } \\
\text { surface roughness during the production of a fine pitch spur gear made of copper. The spur gear } \\
\text { has a pressure angle of } 20^{\circ} \text { and pitch circle diameter of } 70 \mathrm{~mm} \text {. The wire has a diameter of } 0.25 \\
\text { mm and is made of brass. Experiments were conducted according to Taguchi's orthogonal array } \\
\text { concept with five factors and two levels. Thus, Taguchi quality loss design technique is used to } \\
\text { optimize the output responses carried out from the experiments. Another optimization technique } \\
\text { i.e. desirability with grey Taguchi technique has been used to optimize the process parameters. } \\
\text { Both the optimized results are compared to find out the best combination of MRR and surface } \\
\text { roughness. A confirmation test was carried out to identify the significant improvement in the } \\
\text { machining performance in case of Taguchi quality loss. Finally, it was concluded that desirability } \\
\text { with grey Taguchi technique produced a better result than the Taguchi quality loss technique in } \\
\text { case of MRR and Taguchi quality loss gives a better result in case of surface roughness. The } \\
\text { quality of the wire after the cutting operation has been presented in the scanning electron } \\
\text { microscopy (SEM) figure. }\end{array}$ \\
\hline
\end{tabular}

C 2017 Growing Science Ltd. All rights reserved

\section{Introduction}

Nowadays, gears are used in huge amounts in all mechanical devices. The rotating part of the gear has a cut teeth or cog that meshes with another gear to transmit torque, the two gears being of identical shape. Geared devices can change the torque, speed and direction of a power source. The most common situation is for a gear to mesh with another gear; however a gear can also mess with a non-rotating part called as rack, thereby producing translation instead of rotation. Spur gears are produced by either cycloidal profile or involute profile. Majority of the gears are manufactured with a pressure angle of $20^{\circ}$ by involute profile. When two gears mesh each other, there is a chance of mating of involute portion with the noninvolute part of the mating gear. This phenomenon is known as Interference and occurs when the number of teeth on the smaller of two meshing gears is fewer than the required minimum. In order to avoid

* Corresponding author. Tel: +919861394573

E-mail: kitu.kasinath1@gmail.com (K.D. Mohapatra)

(C) 2017 Growing Science Ltd. All rights reserved. doi: $10.5267 /$ j. ijiec.2016.9.002 
interference, Undercutting is done. In a pair of meshing spur gears, the width of the gears along the line of contact is parallel to the gear axes and it shifts its position along the tooth profile curve from top to bottom region of tooth height during the course of action (Maitra). In the recent years, gear technology has gained a wide acceptance in different aspects of engineering.

Wire electric discharge machining is one of the most accurate, precise and most popular machining process in non-traditional machining process (Hsue \& Su, 2004). It is basically a non-conventional machining process to manufacture complex or hard materials that are electrically conductive and difficult to manufacture. It has the ability to cut intricate and complex shapes with a better precision, accuracy and provides a good surface finish. In wire EDM process there is no direct contact between the workpiece material and the tool material, therefore the material of any hardness can be machined by this process as long as it is electrically conductive (Bamberg \& Rakwal, 2009). The material removal occurs by continuous spark discharges at the gap between the tool electrode and the work-piece material connected in an electrical circuit. The dielectric fluid, mainly distilled water provides a cooling effect, is continuously supplied to flow away the cut debris. The sparks caused by the dielectric medium give rise to the temperature in the work-piece material near the point of interaction. The temperatures are high enough to melt and vaporise the metal in the area of electrical discharges (Dauw \& Albert, 1992). The wire used is mainly a brass wire, is continuously supplied from the spool through the work-piece and diameter of the wire ranges from $0.1 \mathrm{~mm}$ to $0.3 \mathrm{~mm}$ (Speeding \& Wang, 1997). Due to the variation in the dimensional accuracy, the wires once used cannot be reused again and it is collected at the bottom of the collection tank (Bovina et al., 1991). In wire EDM, brass, tungsten, copper, aluminium and zinc coated brass are widely applied as tool electrodes. However WEDM is vital machine tool and finds its application in aerospace, nuclear, tool and die making industries, automobile, computer and electronics industries.

\section{Literature review}

Wire EDM is important in several manufacturing process in which precision and accuracy are the most important, while cutting of the material is taken into consideration. According to the literature survey, the output responses mainly material removal rate, accuracy, surface roughness, cutting speed, kerf-width have been investigated and experimented to improve the performance characteristics of the metals.Different authors have performed different research on wire breakage and rupture problems. Tanimura (1977) developed a short circuit detecting system, in which the chock inductance of the pulse generator is adjusted in order to avoid the sparks causing the wire to rupture. Tosun et al. (2004) studied the kerf and material removal rate in wire electrical discharge machining based on Taguchi method. Kinoshita et al. (1982) analyzed the various types of wire breaking. They developed a control system in which they monitored the pulse frequency in order to prevent the wire breakage. (Spedding, 1997a, 1997b) tried to develop a model of WEDM process by using response surface methodology and artificial neural networks and found that the model exactness of both was better. They further attempted to optimize the surface waviness, roughness and speed by using a constrained optimization model. Huse et al. (1999) attempted a model to find the corner cutting of the MRR in the WEDM process in terms of discharge angle by considering the wire deflection. Lin et al. (2001) developed a control strategy in order to improve the accuracy of the corner parts in the wire EDM process based on Fuzzy logic. Qu et al. (2002) proposed a mathematical model for MRR of a cylindrical wire EDM process. Gokler and Ozanozhu (2000) studied the surface roughness on various experimental conditions and relative machining parameters for wire EDM process. Karunamoorthy and Ramakrishnan (2004) proposed a mathematical model using RSM. Jahan et al.(2009) studied using transistor and RC typed generators in order to find the effect of EDM machining. It was found that surface finish was achieved better in RC type pulse generator rather than transistor type pulse generator. Saha et al. (2008) developed a back propagation neural network model and regression model to find the cutting speed and surface roughness of tungsten carbide in wire EDM process. Lee and Li (2003) proposed that when the peak current is less than $16 \mathrm{~A}$, the surface integrity of the EDM machined surface remains intact. 
From the past literature it can be seen that less work has been carried out on optimization in wire EDM process and very few experiments have been conducted in manufacturing of gears. No work has been carried out in comparing the optimization technique for the best suitable parameters in gear cutting process using wire EDM. So the present paper focuses on both experimental and optimization method to show the parameters affecting the output responses by comparing both the techniques.

\section{Design of Experiments and Experimentation}

\subsection{Gear Geometry}

The gear figure is obtained from the suitable software by giving the required number of teeth and pitch circle diameter. The gear has an addendum diameter of $81.66 \mathrm{~mm}$, dedendum diameter of $55.4 \mathrm{~mm}$, tooth width of $9.1 \mathrm{~mm}$ and a base diameter of $65.7 \mathrm{~mm}$. 12 teeth were obtained from the gear and each tooth is cut with one set of parameter repeated once. A total of twelve outputs have been obtained for twelve different runs. Table 1 depicts the gear specifications chosen for the experiment.

Table 1

Gear specifications used for machining of gear

\begin{tabular}{cc}
\hline Gear specifications & Gear Constraints \\
\hline Profile & Involutes \\
Number of teeth & 12 \\
Pressure angle & $20^{\circ}$ \\
Pitch circle diameter & 70 \\
\hline
\end{tabular}

\subsection{Role of copper in manufacturing of gears}

Copper is malleable that is it can be shaped and bent without cracking. Copper is corrosion resistant and it offers high strength the gear. Copper gear is easy to machine and or alone it can be used to make gears. Bronze with copper provides high strength and low friction which is widely used for power gears. Copper is a good conductor of electricity, hence copper gear results in spark proof starting of the engines. Copper gears can also help oil pumps to convey fluids with very little flash points such as benzene and gasoline for transportation of various oils such as diesel, petroleum and lubricant oils at a temperature below $70^{\circ} \mathrm{C}$. Copper gears are used in semiconductor industries in clocks, paper making, radiators, aerospace, printing and mining industries, trucks, electric motors and air brakes. Several researches have been attempted previously, and the authors have concluded that the wire EDM is capable of producing high quality miniature gears.In this present study, more control factors were taken in order to improve the better accuracy of results.A total of 12 sets of experiments i.e. L12 were carried out by taking 5 factors and 2 levels each. The design of experiments consists of input factors like Pulse on time ( $\left.\mathrm{T}_{\mathrm{ON}}\right)$, Pulse off time $\left(\mathrm{T}_{\mathrm{OFF}}\right)$, Wire feed rate $\left(\mathrm{W}_{\mathrm{F}}\right)$, Wire tension $\left(\mathrm{W}_{\mathrm{F}}\right)$ and Servo voltage $\left(\mathrm{S}_{\mathrm{V}}\right)$. Fig. 1 shows a copper plate being cut by a wire EDM machine in the shape of a gear.

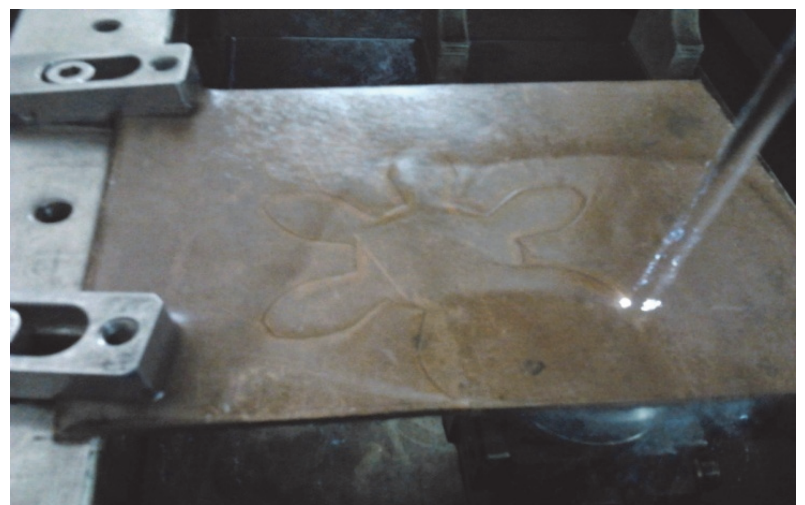

Fig. 1. A gear cut shaped copper plate using Wire EDM 
Since there are 2 levels and 5 input parameters, different optimization technique can be used to optimize the process parameters. However Taguchi quality Loss and desirability with Grey Taguchi optimization method has been chosen in order to compare the optimization to find out the optimal setting for MRR and surface roughness. Based on the literature review and based on the assumptions that each process parameter is independent in this experiment, Taguchi function was used.

Table 2

Selection of parameters and ranges for gear cutting operation

\begin{tabular}{ccccc}
\hline Input Parameters & Symbol & Unit & Level & I \\
\hline & & & 112 & 116 \\
\hline Pulse on time & $\mathrm{T}_{\mathrm{ON}}$ & $\mu \mathrm{s}$ & 57 & 61 \\
Pulse off time & $\mathrm{T}_{\mathrm{OFF}}$ & $\mu \mathrm{s}$ & 4 & 5 \\
Wire feed rate & $\mathrm{W}_{\mathrm{F}}$ & $\mathrm{m} / \mathrm{min}$ & 6 & 7 \\
Wire tension & $\mathrm{W}_{\mathrm{T}}$ & $\mathrm{kg}-\mathrm{f}$ & 20 & 30 \\
Servo Voltage & $\mathrm{S}_{\mathrm{V}}$ & $\mathrm{v}$ & & \\
\hline
\end{tabular}

Table 2 depicts the different input parameters and values taken at different levels. The ranges were chosen according to the machine constraints and literature reviews. The range of Pulse on time is chosen a low of $12 \mu \mathrm{s}$ and a high of $16 \mu \mathrm{s}$, where 1 is the Equi-energy Pulse mode setting of the machine. Similarly Pulse off time varied from 57 and $61 \mu$ s. The cutting operation is done by using a CNC ECOCUT wire EDM machine using dielectric as distilled water.The present work is carried out by using a thick rectangular copper plate of $10 \mathrm{~cm}$ length and width having $3 \mathrm{~mm}$ thickness. The combinations of process parameters obtained were experimented and the output parameters i.e. MRR and surface roughness were calculated for 12 different readings. Table 3 shows the different fixed input parameters taken for machining of gear operation.

Table 3

Fixed parameters used in the experiment

\begin{tabular}{ccc}
\hline Parameters & Symbols & Machine Constraints \\
\hline Wire Type & & Brass \\
Wire Diameter & & $0.25 \mathrm{~mm}$ \\
Peak Current & $\mathrm{I}_{\mathrm{P}}$ & $110 \mathrm{~A}$ \\
Peak Voltage & $\mathrm{V}_{\mathrm{P}}$ & $11 \mathrm{~V}$ \\
Water pressure & $\mathrm{W}_{\mathrm{P}}$ & $1 \mathrm{~kg} / \mathrm{cm}^{2}$ \\
Servo feed rate & $\mathrm{S}_{\mathrm{F}}$ & $2250 \mathrm{~mm} / \mathrm{min}^{2}$ \\
Cutting speed over-ride & $\mathrm{CS}$ & $80 \%$ \\
\hline
\end{tabular}

\subsection{Determination of MRR and surface roughness}

In wire EDM, the material is removed from the work-piece by a series of sparks from electrical discharge. In the present study, the material removal rate was calculated by taking cutting speed $\left(\mathrm{V}_{\mathrm{C}}\right)$, diameter of the wire $(\mathrm{k})$ and work-piece thickness $(\mathrm{h})$ into consideration. In wire EDM, the material removal is more if the spark is increased. It is always good to maximize the MRR. MRR is expressed in terms of $\mathrm{mm}^{3} / \mathrm{min}$. The material removed in wire EDM is given by the formula

$$
\text { MRR }=\mathbf{V c} \times \mathbf{h} \times \mathbf{k}
$$

Cutting speed is calculated by taking length of the wire and time into consideration. The cutting length is determined from the wire EDM machine. The cutting speed is expressed as $\mathrm{mm} / \mathrm{min}$. The cutting speed is given by the following formula

$$
V c=60 \frac{l}{t}
$$


where 1 is the length of the cut wire in $\mathrm{mm}$ and $\mathrm{t}$ is the time of cut in second. The surface roughness (Ra) in wire EDM is an important output parameter, however wire EDM machine provides a good surface finish during machining operation. The roughness during the cut depends upon the input parameters setting control in the machine. For example increase in the Pulse on time may result in increase in spark, and may lead to bad surface finish. However it is important to minimize the surface roughness in order to get a good surface finish. In the present study, the roughness is calculated by using a Talysurf instrument. The roughness of the surface was measured two times on both the left flank and right flank of the gear on its lay and their average was taken in order to calculate the surface roughness for this experiment.

\section{Analysis of the experimentation}

In the present experiment, L12 orthogonal array was carried out for 2 levels and 5 factors for determining the MRR and surface roughness. However the statistical analysis was divided into three phases. In the first phase, MRR and surface roughness was calculated. The second phase consists of determination of ANOVA in order to know the significant factors for each machining response. The final phase is to optimize the responses to know the best combination. Table 4 depicts the output responses obtained during each set of machining operation.

\section{Table 4}

Taguchi L12 array and output results obtained for MRR and Surface roughness

\begin{tabular}{cccccccc}
\hline & \multicolumn{3}{c}{ Input Parameters } & & \multicolumn{2}{c}{ Output Responses } \\
\hline SL Number & $\mathrm{T}_{\mathrm{ON}}$ & \multicolumn{2}{c}{$\mathrm{T}_{\text {OFF }}$} & $\mathrm{W}_{\mathrm{F}}$ & $\mathrm{W}_{\mathrm{T}}$ & $\mathrm{S}_{\mathrm{V}}$ & \multicolumn{2}{c}{ MRR } & Ra \\
\hline 1 & 112 & 57 & 4 & 6 & 20 & 2.43 & 2.05 \\
2 & 112 & 57 & 4 & 6 & 20 & 2.44 & 2.2 \\
3 & 112 & 57 & 5 & 7 & 30 & 2.52 & 2.0 \\
4 & 112 & 61 & 4 & 7 & 30 & 2.01 & 2.05 \\
5 & 112 & 61 & 5 & 6 & 30 & 1.97 & 1.90 \\
6 & 112 & 61 & 5 & 7 & 20 & 2.16 & 1.85 \\
7 & 116 & 57 & 5 & 7 & 20 & 3.22 & 2.10 \\
8 & 116 & 57 & 5 & 6 & 30 & 2.95 & 2.25 \\
9 & 116 & 57 & 4 & 7 & 30 & 2.90 & 2.30 \\
0 & 116 & 61 & 5 & 6 & 20 & 3.12 & 2.50 \\
11 & 116 & 61 & 4 & 7 & 20 & 3.06 & 2.55 \\
12 & 116 & 61 & 4 & 6 & 30 & 2.61 & 2.45 \\
\hline
\end{tabular}

\subsection{Microstructure of the wire}
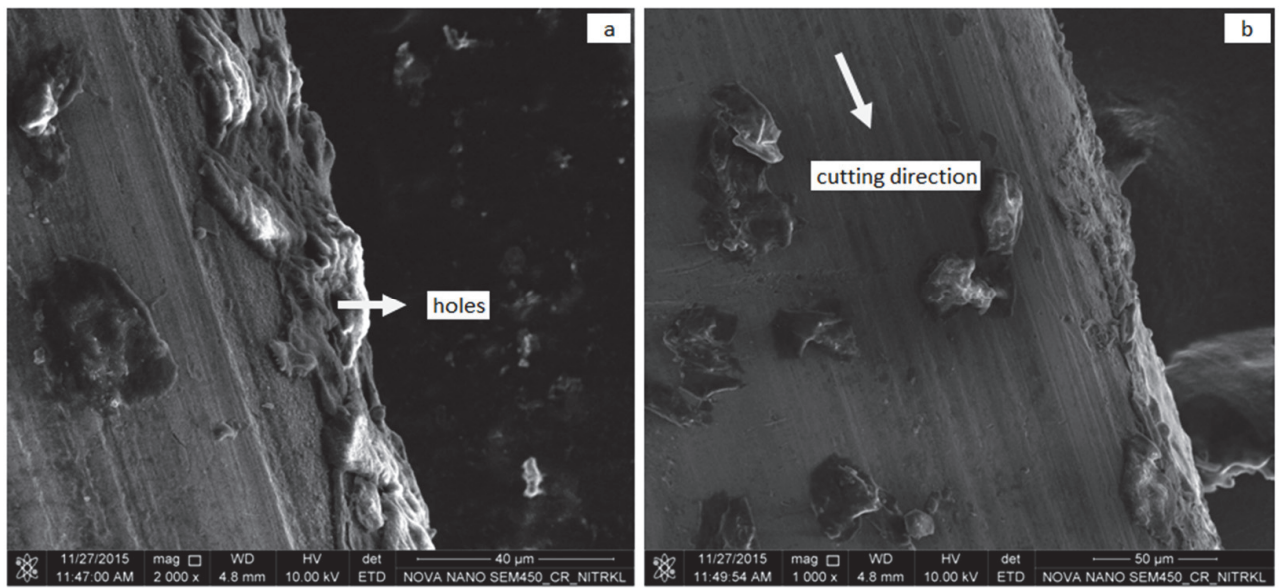

Fig. 2. Micrographs of the brass wire showing (a) holes at 2000X and (b) cutting direction of the wire 
The brass wire that is used for the cutting operation of the gear is being viewed under the scanning electron microscope (SEM). Fig. 2 shows the SEM images of the wire. Fig. 2(a) depicts that after the machining of the work-piece, there is some material removal of the wire. The material also executes some types of holes and burrs which indicate that if further cut with the same wire, the type of finishing operation will not be as good as the previous one. Fig. 2(b) shows the SEM image of cutting direction of the wire. It can be clearly seen that there are some marks towards the downward direction which indicate that the wire cuts the work-piece in that direction.

\section{Optimization technique for the experiment}

In order to know the best results, optimization is done. The optimization is necessary to know the best possible combinations from a given set of results. There are two types of optimization, Single objective optimization and multi objective optimization. Single objective optimization considers each output responses individually with respect to the process parameters used. Multi objective optimization combines all the output responses to one and then considers each response individually with respect to process parameters.

\subsection{Multi objective optimization using Taguchi Quality loss}

Taguchi, a statistical method, was developed by Genichi Taguchi to develop the quality of manufactured goods and is also applied to engineering field. Taguchi design is an orthogonal array method and an efficient tool for the design of high quality manufacturing system. In Taguchi, a loss function is generated from the error. The purpose of this optimization is to maximize the MRR and minimize the surface roughness in order to get the best result. For data processing, higher the better should be taken for MRR and lower the better should be taken for surface roughness.

\subsubsection{Methodology used for calculating Taguchi Quality loss}

Consider the responses.

For Lower the better(LB)

$$
L_{i j}=Y_{i j}{ }^{2}
$$

For Higher the better(HB)

$$
L_{i j}=1 / Y_{i j}{ }^{2}
$$

where, $\mathrm{L}_{\mathrm{ij}}$ is the quality loss function and $\mathrm{y}_{\mathrm{ij}}$ is the ith performance of the response table in the ith trial.

\section{Calculation of Normalized Values}

The data are normalized in order to avoid the effect of using different units and to reduce the variability. It is a transformation function performed to distribute the data evenly on a single input and to scale it into an acceptable range for further analysis.

The normalized function is given by the formula

$$
N_{i j}=\frac{L_{i j}}{L^{*}}
$$

where, $L^{*}=\max L_{i j}$. 
The average is taken for calculating $\mathrm{T}_{\mathrm{ij}}$

The total loss function or theTaguchi Loss function is given by the following formula

$$
T_{i j}=\sum_{i=1}^{n} \mathrm{~W}_{\mathrm{i}} \mathrm{N}_{\mathrm{ij}}
$$

where, Wi is the Weight-age which is always taken as 1.

\section{Calculation of $S / N$ ratio}

The $\mathrm{S} / \mathrm{N}$ ratios are expressed on a decibel scale. The $\mathrm{S} / \mathrm{N}$ ratio can be calculated as the logarithmic transformation of the loss function which is given by

$$
N_{j}=-10 \log T_{i j}
$$

\subsection{Multi objective optimization using Desirability with Grey Taguchi}

The desirability function approach is one of the most widely accepted and used method for multi response optimization process. The idea is based on quality of a process or product that has more than one quality characteristics. The desirability function was proposed by Harrington (1965) using functional forms described by Derringer and Suich (1980). The approach behind this is that the functions are translated to a common scale $([0,1])$, and then the geometric mean are combined to get the overall optimize metric.

Grey Taguchi, also known as grey relational analysis is an important method in grey system theory. This theory was first initiated by Deng to mainly study the uncertainties in system models and to make forecasts and decisions. The meaning of grey originally means black and white. The process of transferring original sequence to comparable sequence is the data processing in this analysis.

\subsubsection{Methodology used for calculating Desirability with grey Taguchi}

The Desirability function is given as

For higher the better,

$$
\mathrm{d}_{\mathrm{r}}{ }^{\max }=\left\{\begin{array}{l}
0 \text { if } \mathrm{y} \leq \mathrm{ymin} \\
\left(\frac{y-y \min }{y \max -y \min }\right)^{r} \text { if } \mathrm{y}_{\min } \leq \mathrm{y} \leq \mathrm{y}_{\max } \\
1 \text { if } \mathrm{y} \geq \mathrm{ymax}
\end{array}\right.
$$

For lower the better,

$$
\mathrm{d}_{\mathrm{r}}{ }^{\min }=\left\{\begin{array}{l}
1 \text { if } \mathrm{y} \leq \mathrm{ymin} \\
\left(\frac{y-y \max }{y \min -y \max }\right)^{r} \text { if } \mathrm{y}_{\min } \leq \mathrm{y} \leq \mathrm{y}_{\max } \\
0 \text { if } \mathrm{y} \geq \mathrm{ymax}
\end{array}\right.
$$

Here $r$ is the desirability index function which is taken as $1 . y$ is the undesirable value. The values of $y_{\max }$ and $y_{\min }$ are chosen by the user. The grey relational coefficient $£ i(\mathrm{k})$ can be calculated as

$$
£ \mathrm{i}(\mathrm{k})=\frac{\Delta \min +\varphi \Delta \max }{\Delta o i(k)+\varphi \Delta \max }
$$


where $\Delta o i(k)$ is the deviation sequence of the reference sequence and $\varphi$ is the identification coefficient whose value lies between 0 and 1 , usually taken as 0.5 . $\Delta \max$ and $\Delta \min$ are the largest and smallest values of each sequence respectively.

The ideal sequence is taken as 1 . In order to find $\Delta o i(k), 1$ is subtracted from each values of $\Delta$.

The final step is to find out the Grey relational grade $(\gamma i)$ which is given by

$$
\gamma i=\frac{1}{n} \sum_{k=1}^{n} £ \mathrm{i}(\mathrm{k})
$$

Table 5

Comparision between Taguchi quality loss and Desirability with Grey Taguchi

\begin{tabular}{|c|c|c|c|c|c|c|}
\hline \multirow{3}{*}{$\begin{array}{c}\text { SL } \\
\text { NUMBER }\end{array}$} & \multicolumn{3}{|c|}{ Taguchi Quality loss } & \multicolumn{3}{|c|}{ Desirability with Grey Taguchi } \\
\hline & \multicolumn{2}{|c|}{$\mathrm{N}_{\mathrm{IJ}}$} & \multirow[t]{2}{*}{$\mathrm{T}_{\mathrm{IJ}}$} & \multicolumn{2}{|c|}{ £i (k) } & \multirow[t]{2}{*}{ GRR } \\
\hline & MRR & $\mathrm{Ra}$ & & MRR & $\mathrm{Ra}$ & \\
\hline 1 & 0.657 & 0.646 & 0.325 & 0.440 & 0.636 & 0.538 \\
\hline 2 & 0.649 & 0.744 & 0.348 & 0.445 & 0.5 & 0.472 \\
\hline 3 & 0.610 & 0.615 & 0.306 & 0.470 & 0.7 & 0.585 \\
\hline 4 & 0.953 & 0.672 & 0.406 & 0.341 & 0.636 & 0.488 \\
\hline 5 & 1 & 0.555 & 0.388 & 0.333 & 0.875 & 0.604 \\
\hline 6 & 0.832 & 0.526 & 0.339 & 0.370 & 1 & 0.685 \\
\hline 7 & 0.373 & 0.678 & 0.262 & 1 & 0.583 & 0.791 \\
\hline 8 & 0.443 & 0.778 & 0.305 & 0.698 & 0.466 & 0.582 \\
\hline 9 & 0.459 & 0.813 & 0.318 & 0.659 & 0.437 & 0.548 \\
\hline 10 & 0.396 & 1.961 & 0.339 & 0.864 & 0.35 & 0.607 \\
\hline 11 & 0.412 & 1 & 0.353 & 0.798 & 0.333 & 0.565 \\
\hline 12 & 0.568 & 0.923 & 0.372 & 0.507 & 0.368 & 0.437 \\
\hline
\end{tabular}

\subsection{Main effect plot diagram for Taguchi Quality loss and Desirability with Grey Taguchi}
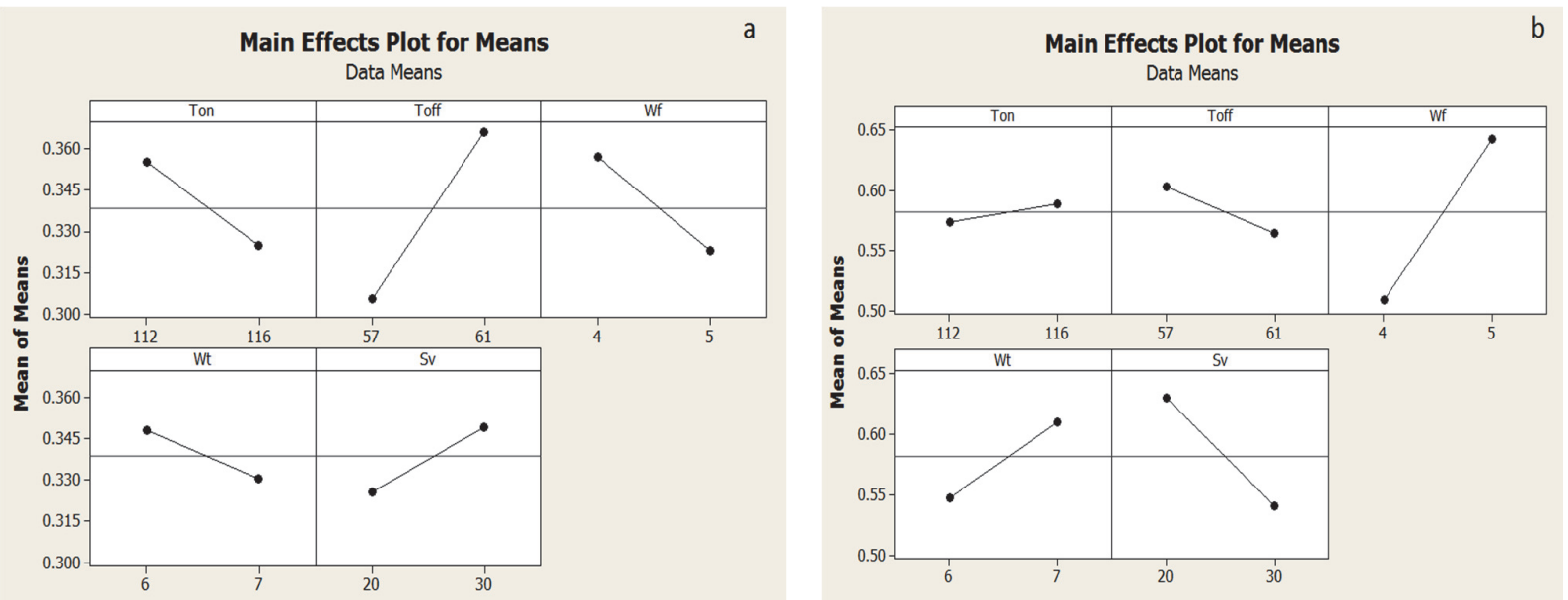

Fig. 3(a).MEP for Taguchi Quality loss; 3(b) MEP for Desirability with Grey Taguchi 
Fig. 3(a) shows the main effect plot for Taguchi Quality loss and Fig. 3(b) shows the main effect plot for Desirability with Grey Taguchi. From Fig. 3(a), it is clear that the highest points of $\mathrm{T}_{\mathrm{ON}}, \mathrm{T}_{\mathrm{OFF}}, \mathrm{W}_{\mathrm{F}}, \mathrm{W}_{\mathrm{T}}$ and $\mathrm{S}_{\mathrm{V}}$ are at $112 \mu \mathrm{s}, 61 \mu \mathrm{s}, 4 \mathrm{~m} / \mathrm{min}, 6 \mathrm{~g}-\mathrm{f}$ and $30 \mathrm{~V}$ respectively. The combinations obtained from this are 112-61-4-6-30, which is not there in the Table 4, for which a confirmation test is needed to know the best values of MRR and Ra from these combinations. From the Fig. 3(b), it is clear that the highest values occur at the point 116-57-5-7-20. The combination is present in the Table 4. The respective MRR and surface roughness for this combination is 3.22 and 2.10 respectively.

Table 6

Result of Confirmatory test for TQL

\begin{tabular}{lcc}
\hline & \multicolumn{2}{c}{ Optimal Machining parameters } \\
\hline & Predicted & Experimental \\
\cline { 2 - 3 } Level & $\mathrm{T}_{\mathrm{ON}} 1 \mathrm{~T}_{\mathrm{OFF}} 2 \mathrm{~W}_{\mathrm{F}} 1 \mathrm{~W}_{\mathrm{T}} 1 \mathrm{~S}_{\mathrm{V}} 2$ & $\mathrm{~T}_{\mathrm{ON}} 1 \mathrm{~T}_{\mathrm{OFF}} 2 \mathrm{~W}_{\mathrm{F}} 1 \mathrm{~W}_{\mathrm{T}} 1 \mathrm{~S}_{\mathrm{V}} 2$ \\
$\mathrm{~S} / \mathrm{N}$ ratio for TQL & -8.352 & -9.897 \\
\hline
\end{tabular}

Confirmation test is done to verify and predict the improvement on the process parameters. Table 6 shows the confirmation test for 112-61-4-6-30 combinations. Confirmation test depicts that the $\mathrm{S} / \mathrm{N}$ ratio for TQL in predicted has an error of $15.6 \%$ than the experimental. In other words, the test results confirm the earlier design and analysis for optimizing the machining parameters. The percentage of error can be calculated by

$\%$ of Error $=\left|\frac{\text { Predicted-experimental }}{\text { experimental }} * 100\right|$

\section{Results and discussion}

\subsection{Comparison of output responses}

The output responses i.e. MRR and surface roughness for different optimization technique has been carried out. Table 7 shows the comparison of output responses of MRR and Ra between TQL and Desirability with Grey Taguchi.

Table 7

Comparision of output responses

\begin{tabular}{ccccc|ccc}
\hline Optimization techniques & \multicolumn{3}{c|}{ Input Parameters } & \multicolumn{3}{c}{ Output responses } \\
\cline { 2 - 8 } & $\mathrm{T}_{\mathrm{ON}}$ & $\mathrm{T}_{\mathrm{OFF}}$ & $\mathrm{W}_{\mathrm{F}}$ & $\mathrm{W}_{\mathrm{T}}$ & $\mathrm{S}_{\mathrm{V}}$ & & $\mathrm{MRR}$ \\
\hline TQL & 112 & 61 & 4 & 6 & 30 & 2.142 & 1.7 \\
Desirability with Grey Taguchi & 116 & 57 & 5 & 7 & 20 & 3.225 & 2.1 \\
\hline
\end{tabular}

From Table 7, it is clear that the best result obtained for MRR and Ra is at different process parameter settings for different optimization method. From the Table 7, it shows that the material removal is good, when the pulse on time is at $112 \mu \mathrm{s}$ and it is better when the $\mathrm{T}_{\mathrm{ON}}$ setting is at $116 \mu \mathrm{s}$ because more is the material removed, better is the result. In this case Desirability with Grey gives the better result for MRR. Similarly for surface roughness, it can be seen from table 7 that when the Pulse on time is at $112 \mu \mathrm{s}$, the roughness tends to be less in case of Taguchi quality loss, which is the best for the result. In other words we can say that the roughness tends to be the best at setting $\mathrm{T}_{\mathrm{ON}} 112 \mu \mathrm{s}$ rather than $\mathrm{T}_{\mathrm{ON}} 116 \mu \mathrm{s}$ in case of Taguchi quality loss.

\subsection{Comparison of Surface plot for MRR and Ra}

Fig. 4(a) and Fig. 4(b) shows the surface plot in between $T_{\mathrm{ON}}$ and $\mathrm{W}_{\mathrm{F}}$ for Taguchi Quality loss and Desirability with Grey Taguchi. The darker region indicates high response values. The surface plot from Fig. 4(a) reveals that the loss function is highest at pulse on time $114 \mu \mathrm{s}$ and wire feed rate $4 \mathrm{~m} / \mathrm{min}$, 
where from the Fig. 4(b) the surface plot reveals that grade function is highest, when the TON is $112 \mu \mathrm{s}$ and wire feed rate $4 \mathrm{~m} / \mathrm{min}$.
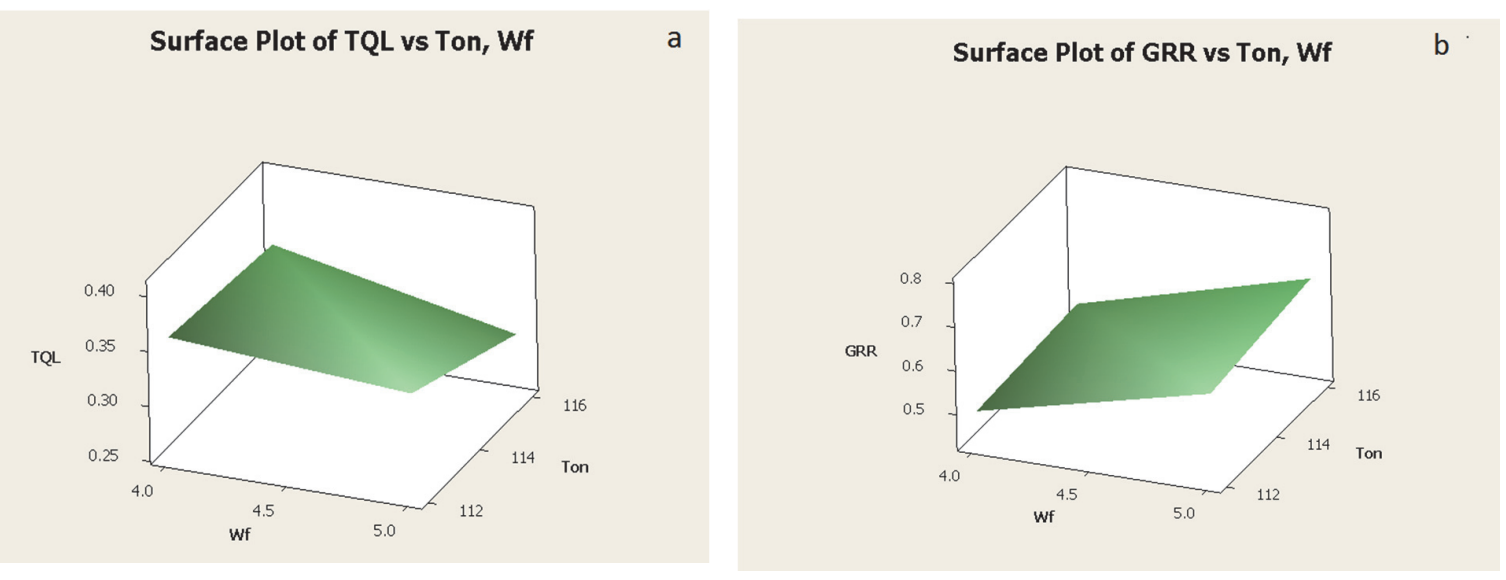

Fig. 4. (a). Surface plot for Taguchi Quality loss with input parameters; 4(b) Surface plot for Desirability with Grey Taguchi with input parameters

\subsection{Effect of process parameters}

The process parameters affect significantly to the response parameters. From the Fig. 3(a), it is clear that with the increase in the pulse on time, wire feed rate and wire tension, the loss function decreases. This is due to the fact that larger sparks causes the wire to move more quickly bearing a greater load to the wire, resulting in a decrease in the loss function. Increase in the pulse on time results in faster cutting speed leading to different values of MRR and Ra. With the increase in pulse off time and servo voltage, the loss function increases. From the Fig. 3(b), it is seen that the Grey Relational Grade function decreases when the pulse off time and servo voltage increases and the Grey Relational Grade function increases when the pulse on time, wire feed rate and wire tension increases. This is exactly the opposite of loss function. This is due to the fact that high discharge energy causes more melting of the metal resulting in an increase in the cuttings speed which results in an increase in Grey Relational Grade. More tension in the wire causes high reaction forces which results in different values of MRR and Ra resulting in an increase in GRR.

\section{Table 8}

ANOVA table for TQL

\begin{tabular}{cccccccc}
\hline Source & DF & Seq SS & Adj SS & Adj MS & F & P & \% Contribution \\
\hline $\mathrm{T}_{\mathrm{ON}}$ & 1 & 0.0020 & 0.018 & 0.018 & 21.31 & 0.006 & 11.97 \\
$\mathrm{~T}_{\mathrm{OFF}}$ & 1 & 0.0090 & 0.079 & 0.079 & 88.93 & 0.000 & 53.89 \\
$\mathrm{~W}_{\mathrm{F}}$ & 1 & 0.0020 & 0.002 & 0.002 & 26.86 & 0.004 & 11.97 \\
$\mathrm{~W}_{\mathrm{T}}$ & 1 & 0.0009 & 0.0006 & 0.0006 & 6.94 & 0.046 & 5.38 \\
$\mathrm{~S}_{\mathrm{V}}$ & 1 & 0.0011 & 0.0011 & 0.0011 & 13.35 & 0.015 & 6.58 \\
\hline Residual Error & 5 & 0.0004 & 0.0004 & 0.0004 & & & 2.39 \\
\hline Total & 10 & 0.0167 & & & & & 100 \\
\hline
\end{tabular}

ANOVA or Analysis of variance is important to know which parameters significantly affect the responses. Table 8 and Table 9 depict the Analysis of variance for loss function and grade function. $\mathrm{P}$ signifies the probability test. If the value of $\mathrm{P}$ is less than 0.05 , then the factor is said to be significant. From Table 8 , it is clear that the significant parameters affecting the loss function are pulse off time followed by wire feed rate, pulse on time, servo voltage and wire tension, where-as while optimizing with Desirability with Grey Taguchi function, the significant factor is wire feed rate only. 
Table 9

ANOVA for Grey Relational Grade

\begin{tabular}{lccccccc}
\hline Source & DF & Seq SS & Adj SS & Adj MS & F & P & \% Contribution \\
\hline $\mathrm{T}_{\mathrm{ON}}$ & 1 & 0.0006 & 0.0009 & 0.0009 & 0.57 & 0.587 & 0.65 \\
$\mathrm{~T}_{\mathrm{OFF}}$ & 1 & 0.0036 & 0.0001 & 0.0001 & 0.06 & 0.844 & 3.90 \\
$\mathrm{~W}_{\mathrm{F}}$ & 1 & 0.0477 & 0.0266 & 0.0266 & 16.28 & 0.015 & 51.67 \\
$\mathrm{~W}_{\mathrm{T}}$ & 1 & 0.0168 & 0.0023 & 0.0023 & 1.44 & 0.443 & 18.20 \\
$\mathrm{~S}_{\mathrm{V}}$ & 1 & 0.0122 & 0.0048 & 0.0048 & 2.96 & 0.335 & 13.21 \\
$\mathrm{~T}_{\mathrm{ON}}{ }^{*} \mathrm{~T}_{\mathrm{OFF}}$ & 1 & 0.0062 & 0.0024 & 0.0024 & 1.49 & 0.437 & 6.71 \\
$\mathrm{~T}_{\mathrm{ON}} \mathrm{W}_{\mathrm{F}}$ & 1 & 0.0005 & 0.000012 & 0.000012 & 0.01 & 0.946 & 0.54 \\
$\mathrm{~T}_{\mathrm{ON}}{ }^{\mathrm{W}} \mathrm{W}_{\mathrm{T}}$ & 1 & 0.0025 & 0.0025 & 0.0025 & 1.56 & 0.430 & 2.70 \\
$\mathrm{~T}_{\mathrm{OFF}} \mathrm{W}_{\mathrm{F}}$ & 1 & 0.0003 & 0.0003 & 0.0003 & 0.22 & 0.719 & 0.32 \\
Residual Error & 1 & 0.0016 & 0.0016 & 0.0016 & & & 1.73 \\
\hline Total & 10 & 0.0923 & & & & & \\
\hline
\end{tabular}

Table 10

Response table for TQL

\begin{tabular}{cccccc}
\hline Level & $\mathrm{T}_{\text {ON }}$ & $\mathrm{T}_{\text {OFF }}$ & $\mathrm{W}_{\mathrm{F}}$ & $\mathrm{W}_{\mathrm{T}}$ & $\mathrm{S}_{\mathrm{V}}$ \\
\hline 1 & 0.355 & 0.305 & 0.3571 & 0.3481 & 0.3259 \\
2 & 0.324 & 0.366 & 0.3232 & 0.3307 & 0.3492 \\
Delta & 0.030 & 0.060 & 0.0339 & 0.0174 & 0.0233 \\
Rank & 3 & 1 & 2 & 5 & 4 \\
\hline
\end{tabular}

Table 11

Response table for Grey Relational Grade

\begin{tabular}{cccccc}
\hline Level & $\mathrm{T}_{\text {ON }}$ & $\mathrm{T}_{\text {OFF }}$ & $\mathrm{W}_{\mathrm{F}}$ & $\mathrm{W}_{\mathrm{T}}$ & $\mathrm{S}_{\mathrm{V}}$ \\
\hline 1 & 0.5738 & 0.6028 & 0.5094 & 0.5476 & 0.6312 \\
2 & 0.5891 & 0.5649 & 0.6427 & 0.6109 & 0.5413 \\
Delta & 0.0152 & 0.0379 & 0.1333 & 0.0634 & 0.0899 \\
Rank & 5 & 4 & 1 & 3 & 2 \\
\hline
\end{tabular}

Table 10 and Table 11 determine the rank of the input parameters used in the experiment. From the response Table 10 it is seen that the most significant parameter is pulse off time which is ranked as 1 . Pulse off time provides a significant contributionto the output responses i.e. MRR and Ra. Similarly from the Table 11, it is concluded that in optimization ofprocess parameters, wire feed rate plays a significant role in optimizing the response parameters i.e. MRR and Ra.

\section{Conclusions}

This paper has described the comparison of two multi objective optimization method of wire EDM process using Taguchi quality loss function and Hybrid optimization method i.e. Desirability with Grey Taguchi method. It was observed that the $F$ value of pulse off time is 88.93 which is found to be highly significant parameter and the percentage of contribution is $53.89 \%$ in case of TQL. However a $\%$ contribution of 51.67 was found while optimising it in Desirability with Grey Taguchi method and wire feed rate was found to be the most significant parameter with $F$ value 16.28. Combining and analysing both the optimization techniques, it was found that wire feed rate is most significant factor in determining MRR and Ra. The $P$ value for $\mathrm{W}_{\mathrm{F}}$ in case of loss function and Hybrid technique is 0.004 and 0.015 respectively. However comparing both the techniques it was found that Desirability with Grey gives the best result for MRR and Taguchi quality loss gives the best result for surface roughness. The authenticity of the developed optimization method was tested and the optimal parametric condition for both the optimization methods is beneficial to the manufacturing communities working on gears as well as wire EDM process. 


\section{References}

Lin, C. T., Chung, I. F., \& Huang, S. Y. (2001). Improvement of machining accuracy by fuzzy logic at corner parts for wire-EDM. Fuzzy sets and systems, 122(3), 499-511.

Dauw, D. F., \& Albert, L. (1992). About the evolution of wire tool performance in wire EDM. CIRP Annals-Manufacturing Technology, 41(1), 221-225.

Gökler, M. I., \& Ozanözgü, A. M. (2000). Experimental investigation of effects of cutting parameters on surface roughness in the WEDM process.International journal of Machine tools and manufacture, 40(13), 1831-1848.

Hsue, W. J., Liao, Y. S., \& Lu, S. S. (1999). Fundamental geometry analysis of wire electrical discharge machining in corner cutting. International journal of machine tools and manufacture, 39(4), 651-667.

Hsue, A. W. J., \& Su, H. C. (2004). Removal analysis of WEDM's tapering process and its application to generation of precise conjugate surface.Journal of materials processing technology, 149(1), 117123.

Jahan, M. P., Wong, Y. S., \& Rahman, M. (2009). A study on the quality micro-hole machining of tungsten carbide by micro-EDM process using transistor and RC-type pulse generator. Journal of materials processing technology, 209(4), 1706-1716.

Kinoshita, N., Fukui, M., \& Gamo, G. (1982). Control of wire-EDM preventing electrode from breaking. CIRP Annals-Manufacturing Technology, 31(1), 111-114.

Lee, S. H., \& Li, X. (2003). Study of the surface integrity of the machined workpiece in the EDM of tungsten carbide. Journal of Materials Processing Technology, 139(1), 315-321.

Maitra, G.M. A handbook of Gear Design. $2^{\text {nd }}$ ed, New Delhi: Tata McGraw-Hill Education Publishing Company.

Qu, J., Shih, A. J., \& Scattergood, R. O. (2002). Development of the cylindrical wire electrical discharge machining process, part 2: surface integrity and roundness. Journal of Manufacturing Science and Engineering,124(3), 708-714.

Rakwal, D., \& Bamberg, E. (2009). Slicing, cleaning and kerf analysis of germanium wafers machined by wire electrical discharge machining. Journal of Materials Processing Technology, 209(8), 37403751 .

Ramakrishnan, R., \& Karunamoorthy, L. (2004). Surface roughness model for CNC wire electro discharge machining. Journal of Manufacturing Technology Today, 3(5), 8-11.

Scott, D., Boyina, S., \& Rajurkar, K. P. (1991). Analysis and optimization of parameter combinations in wire electrical discharge machining. The International Journal of Production Research, 29(11), 21892207.

Spedding, T. A., \& Wang, Z. Q. (1997). Parametric optimization and surface characterization of wire electrical discharge machining process. Precision Engineering, 20(1), 5-15.

Spedding, T.A., \& Wang, Z.G. (1997). Study on modelling of wire EDM process.Journal of Material Processing Technology, 69, 18-28.

Saha, P., Singha, A., Pal, S. K., \& Saha, P. (2008). Soft computing models based prediction of cutting speed and surface roughness in wire electro-discharge machining of tungsten carbide cobalt composite. The International Journal of Advanced Manufacturing Technology, 39(1-2), 74-84.

Tanimura, T. (1977). The properties of the servo gap sensor with wire spark-erosion machining. Annals of the CIRP, 25, 59.

Tosun, N., Cogun, C., \& Tosun, G. (2004). A study on kerf and material removal rate in wire electrical discharge machining based on Taguchi method. Journal of Materials Processing Technology, 152(3), 316-322.

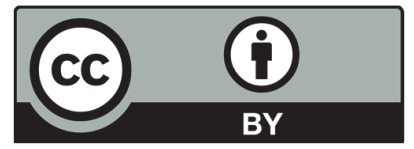

(C) 2016 by the authors; licensee Growing Science, Canada. This is an open access article distributed under the terms and conditions of the Creative Commons Attribution (CCBY) license (http://creativecommons.org/licenses/by/4.0/). 